Original article

\title{
Prevalence and Correlates of Microalbuminuria among Type 2 Diabetes Patients at Muhimbili National Hospital, Dar es Salaam, Tanzania
}

Evelyne Kantarama ${ }^{*}$, Dieudonne Uwizeye ${ }^{2}$, Teddy Mselle ${ }^{3}$

${ }^{1}$ Clinical Biology Department, School of Medicine and Pharmacy, College of Medicine and Health Science, University of Rwanda, Kigali, Rwanda

${ }^{2}$ Development studies, University of Rwanda, Kigali, Rwanda

${ }^{3}$ Biochemistry Department, Muhimbili University of Health and Allied Sciences, Dar Es Salaam, United Republic of Tanzania

*Corresponding author: Evelyne Kantarama. Clinical Biology Department, School of Medicine and Pharmacy, College of Medicine and Health Science, University of Rwanda, Kigali, Rwanda. Email: kantever11@gmail.com, ekantarama@cartafrica.org

\section{Abstract}

\section{Background}

Regular screening for microalbuminuria among type 2 diabetes patients is less common in most low-income countries while it is an early marker of diabetic nephropathy and cardiovascular complications.

\section{Objective}

This study aims to assess the need for regular screening for microalbuminuria among type 2 diabetes patients.

\section{Methodology}

with cross-sectional approach, 124 diabetic patients were recruited at Muhimbili National Hospital, in Tanzania; their age, gender, body mass index, fasting blood sugar levels (by Accu Chek Active Glucometer), random urine albumin levels (by Microalbumin 2-1 Combo Test Strips), and the duration of diabetes were recorded.

\section{Results}

The study indicated that $62.1 \%$ of the participants were microalbuminuric while $2.4 \%$ were macroalbuminuric. The risk of microalbuminuria was 4.55 higher in patients aged 60-69 years (95\% CI: 1.32-16.51), and 17.4 times higher in patients aged 70 and above (95\% CI: 1.49-202.86) compared to individuals aged below 50 years. Patients with high blood sugar level had a risk of 8.09 times higher compared to those with normal blood sugar (CI: 2.53-25.86). Also, the odds were 7.89 higher in patients who lived with diabetes for 10-14 years compared to those lived with the disease less than 5 years (95\% CI:1.33-45.59). 


\section{Conclusion}

The odds of microalbuminuria increased significantly as the patient gets older, with high blood sugar, and the duration of diabetes. Health policies need to establish programs that enhance care at the diabetic clinic through regular screening for microalbuminuria to reduce the risk of developing kidney and cardiovascular complications.

Rwanda J Med Health Sci 2021;4(1):84-97

Keywords: Blood glucose, age, Microalbuminuria, Diabetes Mellitus

\section{Introduction}

The world and Sub-Saharan Africa, in particular, are experiencing a high increase of non-communicable diseases which will continue to lead as the cause of mortality and morbidity until 2030.[1] Currently, type 2 diabetes mellitus is already on top of reported non-communicable diseases and the main cause of chronic illness and deaths worldwide, and it is causing premature deaths, especially in lowincome countries. For instance, in 2013, the majority of deaths caused by diabetes worldwide were among people under the age of 60 years, and the sub-Saharan Africa region accounted for $75 \%$ of these deaths. [2] The data from the International Diabetes Federation in 2009 shows that more than 371 million people globally had diabetes, and this number is predicted to increase to over 550 million by 2030 , with a large number living in low-and middleincome countries.[3] For instance, in 2006, the Tanzania Diabetes Association (TDA) estimated that there were more than 400,000 people with diabetes. [4]

Diabetes mellitus, defined as persistent hyperglycemia, reflects derangements in carbohydrates, fats, and protein metabolism which itself is a consequence of insulin deficiency, insulin resistance, or both.[5] Type 2 diabetes mellitus (T2DM) is common among middleaged and older people, although it can occur at any age.[6] It is mostly associated with insulin resistance and impacts the main organs involved in the carbohydrates and lipids metabolism. T2DM induces glucose production in the liver and overproduction of free fatty acids by fat cells and also impedes glucose uptake in both liver and skeletal muscle.[7] Insulin deficiency occurs following the gradual failure of betacells which produce an insufficient amount of insulin.[8] Most of the people with T2DM live with it for a long time unknowingly as the disease remains asymptomatic until the individual shows signs of diabetes complications. The excess of blood 
glucose, as it takes years to appear or be recognized, silently, destroys the body.[6] The metabolic derangements of long duration, progressively affect the integrity of body cells and sometimes lead to the permanent loss of function for some organs of the body. The first to be affected is the vascular system due to high blood glucose levels and other abnormal metabolites present in the blood which induce endothelial dysfunction. The dysfunctional endothelium is at the heart of developing diabetes complications. [9] These complications mainly include cardiovascular diseases, diabetic neuropathy, amputations, renal failure, and blindness.[3]

The majority of the causes of morbidity and mortality among diabetic patients result from microalbuminuria because of its association with cardiovascular diseases, proliferative retinopathy, peripheral neuropathy, and renal impairments, which, when not controlled, lead to end-stage renal disease (ESRD).[10] Many people with T2DM will show microalbuminuria at the time of diabetes diagnosis.[11] Studies indicated that up to $30 \%$ of people newly diagnosed with T2DM have an abnormal amount of albumin protein in the urine, an indication that they may have overt proteinuria even at diagnosis.[12]
Several studies indicated microalbuminuria as the first sign of diabetic nephropathy. It develops in the very early stages of diabetes mellitus even when the glomerular filtration rate (GFR) is still normal.[13] This stage is very critical in the management of diabetes as studies have shown that when microalbuminuria is detected early, it is easily addressed to prevent the future development of overt diabetic nephropathy.[12,14]

Microalbuminuria does not have symptoms in the earliest stages. Therefore, it is essential to screen for it among T2DM patients to offer optimal protective therapy against renal failure and cardiovascular events. $[15,16]$ However, the screening is not common in SubSaharan Africa even though diabetes is already a serious health challenge in the region. [17] This study intended to assess the need for regular screening for microalbuminuria among type 2 diabetes patients by determining its magnitude and its correlates among those attending the outpatient clinic at Muhimbili National Hospital in Tanzania.

\section{Methods}

\section{Study design, setting, and population}

The study used a cross-sectional design. Data were collected from December 2014 to January 2015 
among outpatients diagnosed with T2DM that attended the diabetes clinic of Muhimbili National Hospital $(\mathrm{MNH})$, the largest hospital in Tanzania located in Dar es Salaam city. The clinic receives T2DM patients twice a week, about 60 patients a day. Patients see a doctor for follow-up once in three to five months, the attendance pattern can change depending on the status of the disease.

\section{Sample size and sampling procedure}

The study involved 124 participants calculated using the formula designed for cross-sectional studies. As a reference, we used the prevalence of microalbuminuria among type 2 diabetes patients found by a study done at Kilimanjaro Christian Medical Centre (KCMC) in Tanzania (29\%).[18] A convenient sampling procedure was used to collect data; participants were recruited based on their scheduled visits to the diabetes clinic. The procedure was appropriate to collect data within the limited time of 2 months and to abide by the working plan of twice a week of the diabetes outpatient clinic of MNH. Around 500 patients attended the clinic during the two months of data collection among whom we recruited the study participants based on predefined inclusion criteria. We only included T2DM patients who did not have any of the known conditions associated with microalbuminuria, including proteinuria, renal diseases, acute illness, hematuria, hepatic and heart-related diseases, polyuria, urinary tract infection, and hypertension. Also, we included patients who accepted to sign the consent to participate in the study.

We identified 146 potential participants among those who attended the clinic during the period of data collection using the patient's clinical sheets available at the outpatients' diabetes clinic of the hospital. Each potential candidate who consented to participate in the study provided a urine specimen which was screened using dipstick strips with 11 parameters. Only individuals whose specimens tested negative for urinary tract infection (leukocytes, nitrites), proteinuria, and glycosuria were included in the study. In total, we selected 124 participants after the screening.

\section{Ethical considerations}

We got the ethical clearance from the Muhimbili University of Health and Allied Sciences (MUHAS) ethical review board and requested permission from the $\mathrm{MNH}$ administration. We explained the purpose and the importance of the study to the patients before enrolment. Participants got hard copies of the consent form written in Swahili, which is the local language, to read and ask questions about 
whatever they could not understand. The consented participants signed the consent form showing their willingness to participate in the study.

\section{Data collection}

\section{Basic information}

We used a structured form for each participant to record information on age, sex, and the duration of diabetes. We recorded the without shoe height and weight of each participant for BMI calculation. We calculated BMI by taking the weight of an individual in kilograms divided by the square of his/her height in meters. We classified patients' weight as the normal weight for BMI of 18.5$24.9 \mathrm{~kg} / \mathrm{m}^{2}$, overweight for BMI between $25-29.9 \mathrm{~kg} / \mathrm{m}^{2}$, and obese for BMI of $30 \mathrm{~kg} / \mathrm{m}^{2}$ and above.

\section{Laboratory procedures}

Capillary fasting blood glucose was tested using Accu-Chek Active Glucometer measuring blood glucose into $\mathrm{mmol} / \mathrm{L}$. A mean value of 7.2 $\mathrm{mmol} / \mathrm{L}$ of blood sugar was considered normal while the value above $7.2 \mathrm{mmol} / \mathrm{L}$ was considered as high.[19] Urine samples were tested for microalbuminuria using Microalbumin 2-1 combo strips (CLIA waived, Inc. 2-1 Creatinine/Microalbumin Rapid Test Strips) as per the manufacturer's instructions. The obtained results of albumin and creatinine were used to calculate the albumin/ creatinine ratio (ACR). The microalbuminuria was defined as a value of albumin to creatinine ratio ranging from $30-$ $300 \mathrm{mg} / \mathrm{g}$ while the value above $300 \mathrm{mg} / \mathrm{g}$ was considered macroalbuminuria.[20]

\section{Data analysis}

We classified participants according to their baseline characteristics that are age, gender, BMI, blood sugar levels, and the duration of diabetes. Then, we cross-tabulated the participants' characteristics with the ratios of albuminuria (the outcome variable) in three levels (normal, micro, macro) to observe its prevalence patterns. The chi-square test was used to assess whether there was a significant association between the albuminuria levels by the baseline characteristics. Finally, we conducted the logistic regression analysis test with a 95\% level of statistical significance to determine the factors associated with microalbuminuria among the baseline characteristics. Age and duration of diabetes were used as continuous variables while gender, BMI, and blood sugar levels were used as categorical variables.

\section{Results}

\section{Baseline characteristics of the study participants by gender}

Table 1 presents the baseline characteristics by gender for the 124 T2DM patients that participated in 
the study. Among the participants, $75(60.5 \%)$ were females and 49 $(39.5 \%)$ males. The majority $(65.4 \%)$ were below the age of 60 , with a quarter being below the age of 50 (40.3\%). Three-quarters of the participants had high blood sugar

Table 1. Baseline characteristics of study participants by gender

\begin{tabular}{|c|c|c|c|c|}
\hline Variable & Categories & $\begin{array}{l}\text { Frequency } \\
\mathrm{N}=124 \mathrm{n}(\%)\end{array}$ & $\begin{array}{l}\text { Females } \\
75(60.5 \%)\end{array}$ & $\begin{array}{l}\text { Males } \\
49(39.5 \%)\end{array}$ \\
\hline \multirow{4}{*}{ Age (in years) } & $\leq 49$ & $31(25.0)$ & $16(12.9)$ & $15(12.1)$ \\
\hline & $50-59$ & $50(40.3)$ & $30(24.3)$ & $20(16.1)$ \\
\hline & $60-69$ & $34(27.4)$ & $23(18.5)$ & $11(8.9)$ \\
\hline & $\geq 70$ & $9(7.3)$ & $6(4.8)$ & $3(2.4)$ \\
\hline \multirow[t]{2}{*}{ Blood sugar } & $\begin{array}{l}\text { Normal }(\leq 7.2 \\
\mathrm{mmol} / \mathrm{L})\end{array}$ & $31(25.0)$ & $19(15.3)$ & $12(9.7)$ \\
\hline & High $(\geq 7.3 \mathrm{mmol} / \mathrm{L})$ & $93(75.0)$ & $56(45.2)$ & $37(29.8)$ \\
\hline \multirow[t]{3}{*}{ BMI } & Normal weight & $43(34.7)$ & $20(16.1)$ & 23 (18.5) \\
\hline & Overweight & 49(39.5) & $26(21)$ & $23(18.5)$ \\
\hline & Obesity & $32(25.8)$ & 29(23.4) & $3(2.4)$ \\
\hline \multirow{4}{*}{$\begin{array}{l}\text { Duration of diabetes } \\
\text { (in years) }\end{array}$} & $\leq 4$ & $48(38.7)$ & $29(23.4)$ & $19(15.3)$ \\
\hline & $5-9$ & $39(31.5)$ & $22(17.7)$ & $17(13.7)$ \\
\hline & $10-14$ & $23(18.5)$ & $16(12.9)$ & $7(5.6)$ \\
\hline & $\geq 15$ & $14(11.3)$ & $8 \quad(6.5)$ & $6(4.8)$ \\
\hline
\end{tabular}

Concerning the body mass index, $39.5 \%$ were overweight whereas $25.8 \%$ were obese. Also, the body mass index was higher in females than in males. The majority $(70.2 \%)$ of the patients had diabetes for less than ten years among which $38.7 \%$ had diabetes for five years or less.

\section{The prevalence of albuminuria}

Table 2 presents the prevalence of albuminuria in levels cross- levels among which female participants had the highest percentage (45.2\%) compared to male participants $(29.8 \%)$. 
percentage of 46.8 for the two groups.

Table 2. The prevalence of albuminuria by the characteristics of the study participants

\begin{tabular}{|c|c|c|c|c|c|c|}
\hline \multirow[b]{2}{*}{ Variable } & \multirow[b]{2}{*}{ Category } & \multirow[b]{2}{*}{$\begin{array}{l}\text { Frequency } \\
N=124\end{array}$} & \multicolumn{4}{|c|}{ Urine albumin levels } \\
\hline & & & $\begin{array}{l}\text { Normal- } \\
\text { albuminuria } \\
44(35.5 \%)\end{array}$ & $\begin{array}{l}\text { Micro- } \\
\text { albuminuria } \\
77 \text { (62.1\%) }\end{array}$ & $\begin{array}{l}\text { Macro- } \\
\text { albuminuria } \\
3(2.4 \%)\end{array}$ & $\begin{array}{l}\text { P- } \\
\text { value }\end{array}$ \\
\hline \multirow[t]{2}{*}{ Gender } & Females & 75 & $27(21.8)$ & 47 (37.9) & $1(0.8)$ & 0.585 \\
\hline & Males & 49 & $17(13.7)$ & $30(24.2)$ & $2(1.6)$ & \\
\hline \multirow[t]{4}{*}{ Age } & $\leq 49$ & 31 & $16(12.9)$ & $15(12.1)$ & $0(0)$ & $0.001^{*}$ \\
\hline & $50-59$ & 50 & $20(16.1)$ & $29(23.4)$ & $1(0.8)$ & \\
\hline & $60-69$ & 34 & $5 \quad(4.1)$ & $29(23.4)$ & $0(0)$ & \\
\hline & $\geq 70$ & 9 & $3 \quad(2.4)$ & $4(3.2)$ & $2(1.6)$ & \\
\hline \multirow{3}{*}{$\begin{array}{l}\text { Blood } \\
\text { sugar }\end{array}$} & Normal & 31 & $20(21.0)$ & $11(8.9)$ & $0(0)$ & \\
\hline & High & 93 & $24(19.4)$ & $66(53.2)$ & $3(2.4)$ & $0.000^{*}$ \\
\hline & Normal & 43 & $14(11.3)$ & $28(22.6)$ & $1(0.8)$ & 0.944 \\
\hline \multirow[t]{2}{*}{ BMI } & Overweight & 49 & $15(12.1)$ & $33(26.6)$ & $1(0.8)$ & \\
\hline & Obese & 32 & $15(12.1)$ & $16(12.9)$ & $1(0.8)$ & \\
\hline \multirow{4}{*}{$\begin{array}{l}\text { Duration of } \\
\text { diabetes } \\
\text { (in years) }\end{array}$} & $\leq 4$ & 48 & $26(21.0)$ & $22(17.7)$ & $0(0)$ & \\
\hline & $5-9$ & 39 & 13 (10.5) & $26(21.0)$ & $0(0)$ & $0.000 *$ \\
\hline & $10-14$ & 23 & $4(3.2)$ & $18(14.5)$ & $1(0.8)$ & \\
\hline & $\geq 15$ & 14 & $1(0.8)$ & 11 (8.9) & $2(1.6)$ & \\
\hline
\end{tabular}

* Significant at 0.05 level

Likewise, the prevalence of microalbuminuria in patients with high blood sugar was relatively high, comprising $53.2 \%$ of all the samples tested. The distribution of albumin levels was significantly associated with the age, blood sugar levels and the duration of diabetes $(\mathrm{P}<0.001)$. However, there was no statistically significant difference in the distribution of the albumin levels by gender and BMI categories.

\section{Correlates of microalbuminuria}

Table 3 presents the results of the logistic regression analysis of the association between microalbuminuria and the selected predictors. The results indicate an increased risk of microalbuminuria as the age of the patient increased. Patients aged between 60-69 years had 4.66 times the risks of microalbuminuria compared to patients aged below 50 years (95\% CI: 1.32-16.51), and the risk increased 17.4 times in patients aged 
70 years and above (95\% CI: 1.49 202.87). Similarly, the risk for microalbuminuria increased with the duration an individual lived with diabetes. Patients who lived with diabetes for 10-14 years had 7.89 times risks of developing microalbuminuria compared to those who lived with the disease less than 5 years (95\% CI: 1.37-45.59); patients with high blood sugar had 8.09 times risks of microalbuminuria compared to those with normal blood sugar (95\% CI: 2.53-25.86).

Table 3. Results of the logistic regression analysis of the association between microalbuminuria and the selected predictors

\begin{tabular}{|c|c|c|c|c|c|c|}
\hline \multicolumn{4}{|c|}{ Univariate model } & \multicolumn{3}{|c|}{ Multivariable model } \\
\hline & $\begin{array}{l}\text { Odds } \\
\text { ratio }\end{array}$ & $95 \% \mathrm{CI}$ & P- value & Odds ratio & $95 \% \mathrm{CI}$ & $\mathrm{P}$ value \\
\hline \multicolumn{7}{|l|}{ Age (in years) } \\
\hline$\leq 49$ & 1 & - & - & 1 & - & - \\
\hline $50-59$ & 3.03 & $1.17-7.83$ & $0.022^{*}$ & 1.99 & $0.66-6.00$ & 0.222 \\
\hline $60-69$ & 4.45 & $1.53-12.97$ & $0.006^{*}$ & 4.66 & $1.32-16.51$ & $0.017^{*}$ \\
\hline$\geq 70$ & 32.45 & $3.80-277.1$ & $0.001^{*}$ & 17.4 & $1.49-202.87$ & $0.023^{*}$ \\
\hline \multicolumn{7}{|c|}{$\begin{array}{l}\text { Duration of diabetes } \\
\text { (in years) }\end{array}$} \\
\hline$\leq 4$ & 1 & - & - & 1 & - & - \\
\hline $5-9$ & 2.08 & $0.89-4.85$ & 0.089 & 2.31 & $0.81-6.64$ & 0.119 \\
\hline $10-14$ & 12.67 & $2.65-60.46$ & $0.001^{*}$ & 7.89 & $1.37-45.59$ & $0.021^{*}$ \\
\hline$\geq 15$ & 7.33 & $1.47-36.66$ & $0.015^{*}$ & 2.46 & $0.34-17.87$ & 0.374 \\
\hline \multicolumn{7}{|l|}{ BMI } \\
\hline Normal weight & 1 & - & - & 1 & - & - \\
\hline Overweight & 0.96 & $0.42-2.20$ & 0.923 & 1.07 & $0.38-3.01$ & 0.899 \\
\hline Obese & 1.84 & $0.69-4.90$ & 0.223 & 0.46 & $0.10-2.09$ & 0.315 \\
\hline \multicolumn{7}{|l|}{ Blood sugar } \\
\hline Normal & 1 & - & - & 1 & - & - \\
\hline High & 10.73 & $3.92-19.41$ & $0.000^{*}$ & 8.09 & $2.53-25.86$ & $0.000^{*}$ \\
\hline \multicolumn{7}{|l|}{ Gender } \\
\hline Female & 1 & - & - & 1 & - & - \\
\hline Males & 1.53 & $0.72-3.26$ & 0.264 & 1.17 & $0.43-3.22$ & 0.753 \\
\hline
\end{tabular}

* Significant at 95\% confidence interval 
However, there was no statistically significant association between the prevalence of microalbuminuria and the body max index of the patients, nor was it associated with gender.

\section{Discussion}

This study assessed the magnitude of microalbuminuria among type 2 diabetes patients and analyzed its correlates to inform the diabetes clinics of the need for regular microalbuminuria screening. Results indicated that the prevalence of

microalbuminuria among type 2 diabetes outpatients at $\mathrm{MNH}$ was $62.1 \%$. Our finding is close to that observed in earlier studies conducted in developing countries similar to Tanzania.[10,21] However, this prevalence is higher compared to what was found 10 years earlier in the same hospital.[22] Several reasons could explain the difference, among which is the ten years-time lapse. It is reasonable that in ten years many things could have happened including an increased number of patients, delayed diagnosis among others. The other reason may be the different methods used in the detection of microalbuminuria. The mentioned study used 24 hours excretion rate whereas ours used an albumin to creatinine ratio. The 24 hours urine albumin excretion rate is considered the gold standard method. However, due to the challenges of imperfect adherence of the patient to the protocol, the method is not suitable to be used in epidemiological research and clinical settings. Therefore, the albumin to creatinine ratio in a random spot urine sample has been the recommended method as it is easy, rapid, and accurate.[19]

The study did not indicate the association between obesity and microalbuminuria, contrary to what was reported in other studies where obesity was found to be a risk factor for microalbuminuria in type 2 diabetes patients.[9] The lack of association could not be attributed to the size of the sample of 124 patients, as the referenced study used a much smaller sample of 60 . Rather, the reason could be the differences in populations, as in our study, T2DM patients had the disease for a relatively shorter period (mean duration of seven years), whereas, in the referenced studies, patients had had the disease for a much more extended period. Equally important, is the fact that in a case-control study done to evaluate the association between obesity and microalbuminuria among nondiabetic patients, a strong association between obesity and microalbuminuria was reported. The same study indicated that microalbuminuria was highly prevalent among obese subjects compared to the controls.[23] It 
seems that this difference may be related to factors other than diabetes which may be linked to obesity and causing microalbuminuria.

The results of the present study also show that the association between microalbuminuria and gender was not statistically significant, which is similar to what was reported.[24] Nevertheless, Malir Cantt, in Pakistan found that microalbuminuria was correlated with female sex,[25] while a study conducted in the Indian population reported a statistically significant correlation between microalbuminuria and male sex.[24] Based on these results we can assume that these variations in the results may be attributed to differences in lifestyle, which could have exposed men and women differently in the different societies involved.

The study shows a significant association of microalbuminuria with age. This finding is similar to the study conducted at a diabetic clinic in King Abdulaziz university hospital, Saudi Arabia.[26] but contrary to what reported in the study conducted at Al-Husain Hospital, Iraq.[21] These conflicting findings may be due to other confounding factors than the age of subjects, such as dyslipidemia, undiagnosed hypertension among others.
Microalbuminuria is considered to be a meaningful early sign of diabetic nephropathy, which by itself is one of the severe complications of diabetes mellitus.[27] Microalbuminuria develops after 5-10 years from diabetes onset.[28] Consequently, we hypothesized that the degree of microalbuminuria would increase as the number of years an individual lived with diabetes would increase. The findings from this study supported our hypothesis as they indicated that the risk of microalbuminuria increased with the number of years an individual lived with diabetes, which agreed with other related studies.[29] However, some studies, like the one conducted by Ibrahim et al., reported no association between the duration of diabetes and the prevalence of microalbuminuria.[21] This difference may be due to other factors such as poor control of blood sugar and being elderly especially considering that T2DM is common in older people. Another factor to take into account is the delayed diagnosis of diabetes given that its signs appear at an advanced stage.

Last, the study investigated the relationship between microalbuminuria and blood glucose levels. The data show that T2DM patients with high blood glucose levels have an increased risk of microalbuminuria compared to T2DM patients with normal blood 
glucose, just as it was reported elsewhere.[30] The patients with high blood glucose levels indicate a high prevalence of microalbuminuria due to that the high blood glucose level increases pressure in the kidney, which leads to the development of microalbuminuria.

\section{Limitations}

The first limitation is that the study did not account for some potential confounders like dyslipidemia, HIV, and hypertension. Consequently, the findings should be interpreted considering this limitation. Secondly, it was not possible to determine the exact date on which a patient developed diabetes. Therefore, the data presented on the duration of diabetes was based on the date a patient was diagnosed and pronounced to have diabetes. The third limitation is that the study was conducted at one hospital, and for a limited period, meaning that if it could have been extended much longer and recruiting patients from various hospitals, probably the findings could have been different. However, we remain confident that the findings of this study are valuable to inform health providers and policymakers on the improvement of care given to patients with diabetes.

\section{Conclusions and Recommendations}

Microalbuminuria is high among patients with T2DM. The most vulnerable patients are those aged between 50 years and 60 years, and those with high glucose levels. The risk for microalbuminuria increases with age and with the duration of diabetes. Gender and BMI are not significantly associated with microalbuminuria. The study recommends diabetes clinics to conduct regular screening for microalbuminuria in T2DM patients to inform clinical decisions to prevent the risk of developing kidney diseases. Screening should be done at diagnosis and repeated regularly on an annual basis, and proper control of blood glucose should be emphasized to reduce the risk of microalbuminuria and kidney damage.

This study was cross-sectional, and the findings are interpreted to the design and the associated limitations and advantages. We recommend further studies to use the findings to design a longitudinal study involving more extended population coverage.

\section{Conflicts of Interest}

No conflicts of interest are associated with this study 


\section{Authors' Contributions}

EK conceived the idea, and designed the study methodology. She carried out the literature review, data collection, and wrote the first draft. DU worked on data analysis and critically revised the manuscript. TM supervised all research activities. All authors read and revised the manuscript and agreed on the final version before submission.

This article is published open access under the Creative Commons Attribution-NonCommercial NoDerivatives (CC BYNC-ND4.0). People can copy and redistribute the article only for noncommercial purposes and as long as they give appropriate credit to the authors. They cannot distribute any modified material obtained by remixing, transforming or building upon this article.

https://creativecommons.org/licenses / by-ncnd/4.0/

\section{References}

1. Hall V, Thomsen R, Henriksen O, Lohse N. Diabetes in Sub Saharan Africa 1999-2011: Epidemiology and public health implications. A systematic review. BMC Public Health [Internet]. BioMed Central Ltd; 2011;11:564. Available from: http://www.biomedcentral.com/ 1 471-2458/11/564

2. International Diabetes Federation. DIABETES ATLAS. 6th editio. 2013.

3. Unwin N, Whiting $\mathrm{D}$, Gan $\mathrm{D}$, Jacqmain O, Ghyoot G, IDF. IDF
Diabetes Atlas. Fourth Edi. 2009.

4. Ramaiya K. Setting up diabetes clinics in Tanzania. Pract Diabetes Int. 2006;23:339-40.

5. Aldukhayel A. Prevalence of diabetic nephropathy among type 2 diabetic patients in some of the arab countries. Int $J$ Heal Sci. 2017;11:60-3.

6. Sheikh SA, Baig JA, Iqbal T, Kazmi T, Baig M, Husain SS. Prevalence of microalbuminuria with relation to glycemic control in type-2 diabetic patients in Karachi. $J$ Ayub Med Coll Abbottabad. 2009;21:83-6.

7. Jan Koolman K-HR. Color atlas of biochemistry. 2nd editio. Trends Biochem. Sci. New york; 2005.

8. Loghmani E. Type 1 and Type 2 . Diabetes Mellitis. 2005. p. 167-82.

9. Prasad KD, Rajaseker P. Study of microalbuminuria as a cardiovascular risk factor in type 2 diabetes mellitus. Asian $J$ Pharm Clin Res. 2012;5:42-3.

10. Bhaskar Thakkar, Khitij Arora, Ritesh Vekariya, Mohsin Lulania ASA. Prevalence of Microalbuminuria in Newly Diagnosed Type 2 Diabetes Mellitus. Natl $J$ Integr Res Med. 2011;2:22-5. 
11. Salah R. Saleh Ben Hamed1, Pajica Pavkoviæ2@eljko Metelko2. Microalbuminuria and Diabetes Mellitus. Diabetol Croat [Internet]. 2002;31:209-21. Available from: http:/ /www.idb.hr/diabetologia/ 02no4-2.pdf

12. Manjunatha B. K. Goud, Sarsina O. Devi BN and SB. Bio-Chemical Aspects, Pathophysiology of Microalbuminuria and Glycated Hemoglobin in Type 2 Diabetes Mellitus. Pathophysiol Complicat Diabetes Mellit. 2013. p. 29.

13. A.C. Buch, M. Dharmadhikari NKPSSC and HK. Microalbuminuria: an Early Detector of Diabetic and. Int $J$ Basic Appl Med Sci. 2012;2:21825.

14. Ahmedani MY, Hydrie MZI, Iqbal A, Gul A, Mirza WB, Basit A. Prevalence of microalbuminuria in type 2 diabetic patients in Karachi: Pakistan - A multi-center study. $J$ Pak Med Assoc. 2005;55:382-6.

15. Knudsen ST, Mosbech TH, Hansen B, Kønig E, Johnsen PC, Kamper AL. Screening for microalbuminuria in patients with type 2 diabetes is incomplete in general practice. Dan Med $J$. 2012;59.

16. Jorge L. Gross, Mirela J. De
Azevedo, Sandra P. Silveiro, Luis Henrique Canani, Maria Luiza Caromori TZ. Diabetic Nephropathy: Diagnosis, Prevention, and Treatment. Diabetes Care. 2005;28:176-88.

17. Mubarakali N Janmohamed, Samuel E Kalluvya, Andreas Mueller, Rodrick Kabangila, Luke R Smart, Jennifer A Downs RNP. Prevalence of chronic kidney disease in diabetic adult outpatients in Tanzania. BMC Nephrol [Internet]. BMC Nephrology; 2013;14. Available from: BMC Nephrology

18. S Ghosh, I Lyaruu KY. Prevalence and factors associated with microalbuminuria in type 2 diabetic patients at a diabetes clinic in northern Tanzania. $J$ Diabetes Mellit [Internet]. 2012;20. Available from: http:/ / www.scielo.br/scielo.php? script $=$ sci_arttext $\&$ pid $=$ S0100879X2006000800006\&lng=en\&nr $\mathrm{m}=$ iso\&tlng=en

19. American Diabetes Association. Standards of medical care for patients with diabetes mellitus. Diabetes Care. 2003;26:33-47.

20. De Zeeuw D, Parving $\mathrm{H}-\mathrm{H}$, Henning RH. Microalbuminuria as an Early Marker for Cardiovascular Disease. J Am Soc Nephrol. 2006;17:2100-5. 
21. Israa H. Ibrahim, Haider Kamil Zaidan, Qasim M. Ali Al Ameri, Mufeed J.Ewadh AHAS. The Prevalence of Microalbuminuria in Type 2 Diabetes Mellitus Patients in Al-Husain Hospital in Karbala Province- Iraq. Res Biotechnol. 2012;3:14-21.

22. Lutale JJK, Thordarson $\mathrm{H}$, Abbas ZG, Vetvik K. Microalbuminuria among type 1 and type 2 diabetic patients of African origin in Dar Es Salaam, Tanzania. BMC Nephrol. $2007 ; 8$.

23. Pavan M, Ranganath R, Chaudhari AP, Shetty M. Obesity as an independent risk factor for the development of microalbuminuria. Nephrourol Mon. 2011;3:160-3.

24. Chowta N, Pant P, Chowta M. Microalbuminuria in diabetes mellitus: Association with age, sex, weight, and creatinine clearance. Indian J Nephrol. 2009;19:53.

25. Ahmed S, Ahmad SA. Gender difference and relationship of insulin resistance with microalbuminuria type-2 diabetes. $J$ Coll Physicians Surg Pakistan. 2010;20:26-32.

26. Al-Shaikh1 A. Prevalence of Microalbuminuria in Type 2 Diabetes Mellitus at A Diabetic Clinic in King Abdulaziz University
Hospital. Pak J Med Sci .April. 2007;23:223-6.

27. Glassock RJ. Is the presence of microalbuminuria a relevant marker of kidney disease? Curr Hypertens Rep. 2010;12:364-8.

28. Vujičić B, Turk T, Crnčević-Orlić Ž, Đorđević G, Rački S. Diabetic Nephropathy. Pathophysiol Complicat Diabetes Mellitus. 2012. p. 71-96.

29. Pasko N, Toti F, Strakosha A, Thengjilli E, Shehu A, Dedej T, et al. Prevalence of microalbuminuria and risk factor analysis in type 2 diabetes patients in Albania: The need for accurate and early diagnosis of diabetic nephropathy. Hippokratia. 2013;17:337-41.

30. Iranparvar Alamdari $\mathrm{M}$, Aminisani N, Bashardoost B, Shamshirgaran SM, Khodamoradzadeh M, Shokrabadi M OB. Prevalence and Risk Factors of Microalbuminuria in Type 2 Diabetic Patients in a Diabetic Clinic of Ardabil-Iran. Int $J$ Endocrinol Metab. 2006;4:8-12. 